Check for updates

Cite this: RSC Adv., 2017, 7, 41936

\title{
Probing the thermal-enhanced catalytic activity of CO oxidation over Pd/OMS-2 catalysts +
}

\author{
Xin Liu, Qiulin Zhang, (D) * Ping Ning, * Qixian Liu, Zhongxian Song and Yankang Duan \\ The present research has probed the effect of different thermal-treatment temperatures on the catalytic \\ activity of $\mathrm{CO}$ oxidation and the physio-chemical properties of an OMS-2 supported palladium catalyst. \\ The catalytic activity of $\mathrm{Pd} / \mathrm{OMS}-2$ increased with an increase in the thermal-treatment temperature \\ from 300 to $500{ }^{\circ} \mathrm{C}$. The optimal Pd/OMS-2 catalyst exhibited over $99 \% \mathrm{CO}$ conversion at $35{ }^{\circ} \mathrm{C}$. An \\ elevated thermal-treatment temperature up to $500{ }^{\circ} \mathrm{C}$ led to a decrease in OMS-2 crystallinity and \\ surface chemisorbed oxygen $(-\mathrm{OH})$, while the surface atomic ratios of oxygen/Mn and palladium \\ increased with the calcination temperature. A high thermal-treatment temperature above $500{ }^{\circ} \mathrm{C}$ led to \\ the phase transformation of OMS-2 into $\mathrm{Mn}_{2} \mathrm{O}_{3}$, and an abrupt alteration in the $\mathrm{Pd}$-support interaction \\ and deactivation of the Pd/OMS-2 catalyst.
}

Received 16th July 2017

Accepted 15th August 2017

DOI: $10.1039 / \mathrm{c} 7 \mathrm{ra07814e}$

rsc.li/rsc-advances

enhance the dispersion of palladium and the redox properties

\section{Introduction}

Catalytic oxidation of carbon monoxide (CO) has been widely explored in the fields of low-caloric-value gas catalytic combustion, automobile exhaust purification, indoor air cleaning and academic research. ${ }^{1,2}$ Supported $\mathrm{Au}^{,}{ }^{3} \mathrm{Ag}^{4}$ and platinum group metals (PGMs) ${ }^{5}$ have been explored and regarded as active for a low-temperature catalytic oxidation of $\mathrm{CO}$ approach at below room temperature. In terms of commercial application, palladium-based catalysts have been applied to $\mathrm{CO}$ and hydrocarbons (HC) from automobile and industrial exhausts due to their reasonable price, superior lowtemperature activity and stability. ${ }^{6}$ Multi-valence transitional and rare-earth metal oxides (oxides of $\mathrm{Co}, \mathrm{Mn}, \mathrm{Fe}, \mathrm{Ni}, \mathrm{Cu}, \mathrm{Ce}$, etc.) have been known to have oxygen vacancies, excellent oxygen storing capacity (OSC) and redox properties. ${ }^{7-9}$ Since CO adsorption, oxygen storing and transfer capacity are critical for the low-temperature catalytic oxidation of $\mathrm{CO}$ over metal oxide supported palladium catalysts, there remains a substantial amount of work to optimize oxygen vacancies, OSC and the surface dispersion of palladium over multi-valence metal oxide supported palladium catalysts. Molecular sieves with ordered porosity are preferred to enhance the stability and surface dispersion of palladium, while multi-valence manganese oxides are known for their excellent OSC and redox properties. Octahedral molecular sieves (OMS-2) simultaneously contain multivalence $\mathrm{Mn}^{2+}, \mathrm{Mn}^{3+}, \mathrm{Mn}^{4+}$ manganese oxide and the ordered $2 \times 2$ microchannels of molecular sieves. ${ }^{10}$ However, in order to

Faculty of Environmental Science and Engineering, Kunming University of Science and Technology, Kunming, 650500, PR China. E-mail: qiulinzhang_kmust@163.com; ningping_58@126.com; Tel: +86-871-65170905

$\dagger$ Electronic supplementary information (ESI) available. See DOI: 10.1039/c7ra07814e of Pd/OMS-2, there remain great efforts to optimize the morphology and surface chemical properties of the OMS-2 structure. In our previous work, ${ }^{11}$ we found that different preparation methods have an obvious effect on the crystallinity, morphology, surface chemical properties and catalytic oxidation of the Pd/OMS-2 catalysts. OMS-2 nanorods prepared by a hydrothermal method exhibit optimal catalytic properties. In recent years, a facile calcination-enhanced redispersion of palladium over metal oxide supported Pd catalysts has been reported to be active for low-temperature $\mathrm{CO}$ oxidation. ${ }^{12,13}$ Despite a substantial amount of work on the thermal stability of OMS-2,,$^{14,15}$ to the best of our knowledge, the thermal-enhanced catalytic activity of CO oxidation over a Pd/OMS-2 catalyst has rarely been reported.

Our interest has been attracted in exploring the effect of elevating thermal-treatment temperature on the phase composition, oxygen vacancies, surface chemical properties and catalytic activity of $\mathrm{CO}$ oxidation over Pd/OMS-2 catalysts.

\section{Experimental}

\subsection{Catalyst preparation}

2.1.1 Preparation of OMS-2. All OMS-2 supports are prepared with a conventional hydrothermal method, as described previously. ${ }^{11}$ In a typical procedure, $19.3 \mathrm{mmol}$ of $\mathrm{Mn}\left(\mathrm{CH}_{3} \mathrm{COO}\right)_{2} \cdot 4 \mathrm{H}_{2} \mathrm{O}, 27.8 \mathrm{mmol}$ of $\mathrm{KMnO}_{4}$ and $1 \mathrm{~mL}$ of concentrated nitric acid were added to $64 \mathrm{~mL}$ of distilled water with stirring. The mixture was then transferred into a Teflonlined stainless steel autoclave and hydrothermally treated at $100{ }^{\circ} \mathrm{C}$ for $24 \mathrm{~h}$. The resulting precipitate was filtered, washed with deionized water, dried at $100{ }^{\circ} \mathrm{C}$ overnight and calcined at $350{ }^{\circ} \mathrm{C}$ for $3 \mathrm{~h}$ with a heating rate of $3{ }^{\circ} \mathrm{C} \mathrm{min}^{-1}$. 
2.1.2 Preparation of Pd/OMS-2. Pd/OMS-2 catalysts are prepared with an impregnation method using palladium nitrate as precursor with a palladium content of $1 \%$ (wt $\%)$. The above prepared OMS-2 has been impregnated with an aqueous solution of $\mathrm{Pd}\left(\mathrm{NO}_{3}\right)_{2}$ and dried at $70{ }^{\circ} \mathrm{C}$. The dried powders were calcined at $300,400,500$ and $600{ }^{\circ} \mathrm{C}$ and denoted by Pd/OMS-2300, Pd/OMS-2-400, Pd/OMS-2-500, Pd/OMS-2-600, respectively. For example, $\mathrm{Pd} / \mathrm{OMS}-2-500$ means calcining $\mathrm{Pd}\left(\mathrm{NO}_{3}\right)_{2}$ impregnated OMS-2 at $500{ }^{\circ} \mathrm{C}$ for $4 \mathrm{~h}$ with a heating rate of $3{ }^{\circ} \mathrm{C} \mathrm{min}{ }^{-1}$.

\subsection{Catalyst characterization}

$\mathrm{X}$-ray powder diffraction (XRD) analysis was performed on a Bruker D8 Advance diffractometer system, with an operating voltage of $40 \mathrm{kV}$ and a current of $40 \mathrm{~mA}$, using $\mathrm{Cu}-\mathrm{Ka}$ radiation $(\lambda=1.5406 \mathrm{~nm})$ and a graphite monochromator. The samples were investigated in the $2 \theta$ range from 10 to $70^{\circ}$ at a scanning speed of $0.03^{\circ} \mathrm{s}^{-1}$. X-ray photoelectron spectroscopy (XPS) tests were carried out on an ULVAC PHI 5000 Probe-II spectrometer using $\mathrm{Al} \mathrm{K}_{\alpha}$ radiation under UHV. The $\mathrm{C} 1 \mathrm{~s}$ peak $(284.8 \mathrm{eV})$ was used for the calibration of the binding energy values. The surface atomic concentrations of $\mathrm{Mn}, \mathrm{Pd}$, and $\mathrm{O}$, as well as the peak areas were determined with the XPS Peak Fit (Version 4.0, AISN Software Inc.) software. Transmission electron microscopy (TEM) tests were measured on a FEI Tecnai G220 transmission electron microscope, using an accelerating voltage of $200 \mathrm{kV} . \mathrm{N}_{2}$ adsorption/desorption tests were carried out on a Micromeritics TriStar II 3020 instrument at $77 \mathrm{~K}$ using liquid $\mathrm{N}_{2}$ as adsorbent. Specific surface areas (SSAs) were determined by the BrunauerEmmett-Teller (BET) equation. The pore volume was determined from the adsorption isotherms. Pore size distributions were determined by the non-local density functional theory (NLDFT). The low-temperature $\mathrm{H}_{2}$-temperature programmed reduction $\left(\mathrm{H}_{2}\right.$-TPR) tests were performed on a homemade $\mathrm{U}$ shaped quartz-tube fixed-bed reactor (i.d. $3 \mathrm{~nm}$ ). A $10 \mathrm{mg}$ sample and $30 \mathrm{mg}$ of quartz sand were mixed and filled for each measurement. The samples were pre-treated in flowing $\mathrm{N}_{2}$ (30 $\mathrm{mL} \min ^{-1}$ ) at $300{ }^{\circ} \mathrm{C}$ for $60 \mathrm{~min}$ and then cooled to $0{ }^{\circ} \mathrm{C}$. After that, all $\mathrm{H}_{2}$-TPR runs were performed from 0 to $90{ }^{\circ} \mathrm{C}$ under $5 \%$ $\mathrm{H}_{2}$ in Ar with a heating rate of $92{ }^{\circ} \mathrm{C} \min ^{-1}$. Prior to the reaction, the catalysts were pre-treated in flowing $\mathrm{N}_{2}\left(30 \mathrm{~mL} \mathrm{~min}^{-1}\right)$ at $300{ }^{\circ} \mathrm{C}$ for $60 \mathrm{~min}$ and then cooled to $0{ }^{\circ} \mathrm{C}$. A thermal conductivity detector (TCD) was used to monitor the online consumption of $\mathrm{H}_{2}$. Raman tests were performed on a Renishaw inVia Laser micro confocal Raman spectrometer system equipped with a $50 \times$ Leica objective lense to select the target area (spot) of the sample. Laser Raman tests were carried out on the same spot irradiated by a visible Ar ion laser $(514.5 \mathrm{~nm})$. Prior to the test, steady-flow argon was introduced into the catalyst held at $25{ }^{\circ} \mathrm{C}$ for $30 \mathrm{~min}$.

\subsection{Catalytic activity test}

Catalytic activity of $\mathrm{CO}$ oxidation was studied in a down-flow quartz-tube reactor (i.d. $=6 \mathrm{~mm}$ ) with a K-type thermocouple enclosed to monitor the reaction temperature. $200 \mathrm{mg}$ of catalyst was used for each reaction and the total gas flow rate was $50 \mathrm{~mL} \min ^{-1}$ under atmospheric pressure. The reaction gas contents consist of $1 \% \mathrm{CO}(\mathrm{vol} \%)$ and $10.5 \% \mathrm{O}_{2}$ (vol\%) balanced with $\mathrm{N}_{2}$. The gas components were detected by a gas chromatograph with a TDX-01 column, a methanator and a flame ionization detector (FID) under steady-state conditions. The conversion of $\mathrm{CO}$ oxidation was calculated using the following equation:

$$
\mathrm{CO} \text { conversion }(\%)=\frac{[\mathrm{CO}]_{\text {in }}-[\mathrm{CO}]_{\text {out }}}{[\mathrm{CO}]_{\text {in }}} \times 100
$$

where $[\mathrm{CO}]_{\text {in }}$ is the $\mathrm{CO}$ concentration in the feed gas and $[\mathrm{CO}]_{\text {out }}$ is the $\mathrm{CO}$ concentration in the effluent gas.

\section{Results and discussion}

\subsection{Catalytic activity}

It can be seen from Fig. 1 that the conversion of CO catalytic oxidation followed the orders of: Pd/OMS-2-500 > Pd/OMS-2-400 $>$ Pd/OMS-2-300 > Pd/OMS-2-600. Over 99\% CO conversion could be obtained by Pd/OMS-2-300, Pd/OMS-2-400 and Pd/ OMS-2-500 at $35{ }^{\circ} \mathrm{C}$, approaching room temperature. It should be noted that Pd/OMS-2-500 exhibits over 96\% CO conversion below $20{ }^{\circ} \mathrm{C}$. Over $96 \%$ CO conversion could also be obtained by Pd/OMS-2-400 and Pd/OMS-2-500. Pd/OMS-2-600 attained 99\% CO conversion at no more than $50{ }^{\circ} \mathrm{C}$. The overall catalytic conversion of $\mathrm{CO}$ oxidation increases with the calcination temperature of the palladium impregnated OMS-2. While a high calcination temperature above $500{ }^{\circ} \mathrm{C}$ may lead to an abrupt decrease in catalytic activity. Since the concentration of $\mathrm{O}_{2}$ is over $9 \%(\mathrm{v} / \mathrm{v})$, much higher than the CO concentration, the reaction can be simplified to zero order with respect to oxygen and +1 with respect to $\mathrm{CO}$ for low $\mathrm{CO}$ concentration. The optimal Pd/OMS-2-500 exhibits an apparent activation energy of $12.8 \mathrm{~kJ} \mathrm{~mol}^{-1}$ (Fig. S1†). Therefore, it has attracted our great interest to further explore the potential reasons for this thermally-induced elevated activity and abrupt deactivation.

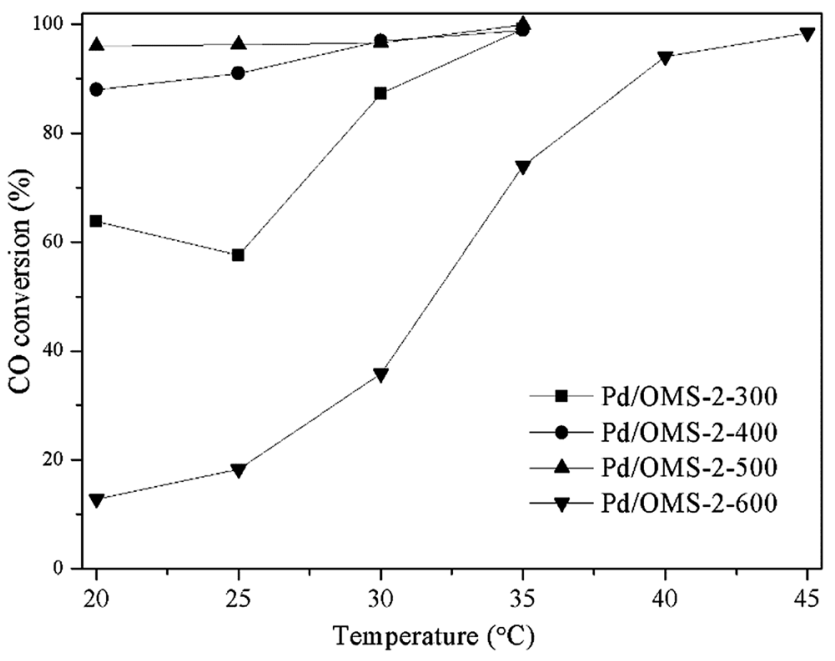

Fig. 1 Conversion of $\mathrm{CO}$ catalytic oxidation over various catalysts (1.0 vol\% CO, 10.5 vol\% $\mathrm{O}_{2}, \mathrm{~N}_{2}$ balanced and GHSV of $15000 \mathrm{~mL} \mathrm{~g}^{-1}$ $\left.\mathrm{h}^{-1}\right)$. 


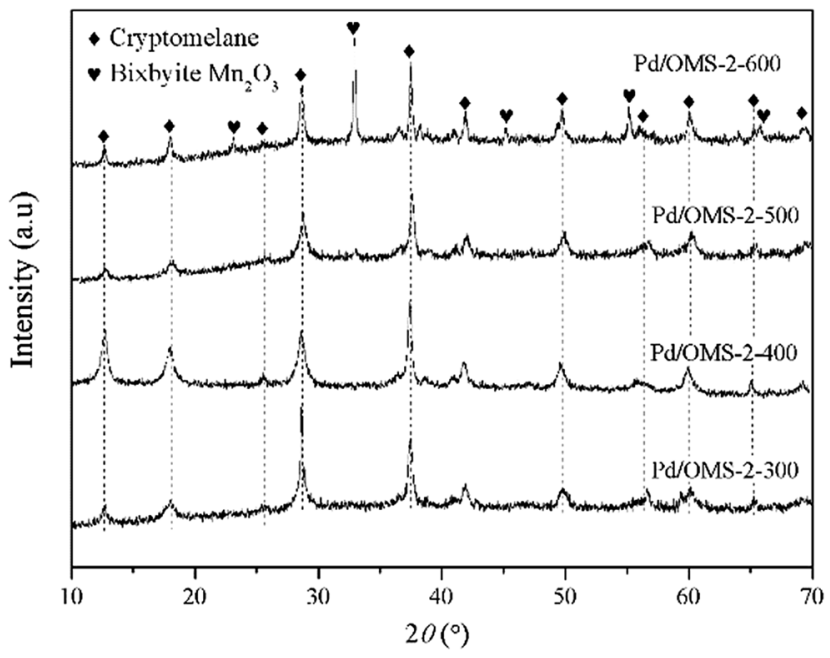

Fig. 2 X-ray diffraction (XRD) patterns of the various catalysts.

\subsection{XRD analysis}

X-ray diffraction (XRD) spectra of various catalysts are shown in Fig. 2. All samples show obvious diffraction peaks of cryptomelane $\mathrm{K}_{2-x} \mathrm{Mn}_{8} \mathrm{O}_{16}$ structure (PDF\# 44-1386), indicating the existence of an octahedral molecular sieve (OMS-2) structure. The intensity of the diffraction peaks decreased when the calcination temperature increased from 300 to $500{ }^{\circ} \mathrm{C}$. Therefore, it should be concluded that a relatively high calcination temperature is preferred to decrease the crystallinity. Obvious diffraction peaks of bixbyite $\mathrm{Mn}_{2} \mathrm{O}_{3}$ (PDF\# 41-1442) could also be seen from the pattern of Pd/OMS-2-600, indicating that a relatively high calcination temperature beyond $500{ }^{\circ} \mathrm{C}$ could result in the formation of highly-crystalline bixbyite $\mathrm{Mn}_{2} \mathrm{O}_{3}$ and
$\mathrm{K}_{2-x} \mathrm{Mn}_{8} \mathrm{O}_{16}$. A potential phase transformation and sintering of the OMS-2 structure may have happened when the calcination temperature shifted from 500 to $600{ }^{\circ} \mathrm{C}$. No obvious characterization peaks of palladium species could be observed from any of the samples, indicating that palladium species existed in the form of highly dispersed non-crystalline species or semicrystals beyond the detection limit of XRD analysis. Overall, it could be concluded that no sintering of palladium crystals could be observed from any of the samples within the detection limits of the XRD technique. Crystallinity decreased with an elevation of the calcination temperature from 300 to $500{ }^{\circ} \mathrm{C}$, while the catalytic activity increased with the thermal-treatment temperature.

\section{$3.3 \quad \mathrm{~N}_{2}$ adsorption-desorption tests}

$\mathrm{N}_{2}$ adsorption-desorption isotherms of various samples are shown in Fig. 3. Hysteresis loops of all samples starting at $P / P_{0}$ $\geq 0.75$ and terminating at $P / P_{0}$ approach 1.0 , indicating the presence of interparticle spaces and an abundance of ordered micropores over OMS-2's primitive topological structure (0.46 nm of $2 \times 2$ microchannels). The NL-DFT pore size distributions (PSD) of various samples are listed in Fig. 4. No obvious gradual uptakes or inflection points approaching $P / P_{0}$ $=0$ could be observed, indicating the low volumes of micropores in all the samples, despite the ordered 1-D microchannels of the OMS-2 structure. It should be noted that a majority of the OMS-2 reported previously exhibit the morphology of nanoparticles or nanorods, which may facilitate the formation of interparticle space. While our present PSD results (Fig. S2 $\dagger$ ) indicate a character which is more like interparticle space than the ordered microchannels of an OMS-2 structure. However, further morphological studies of TEM and STEM are required to

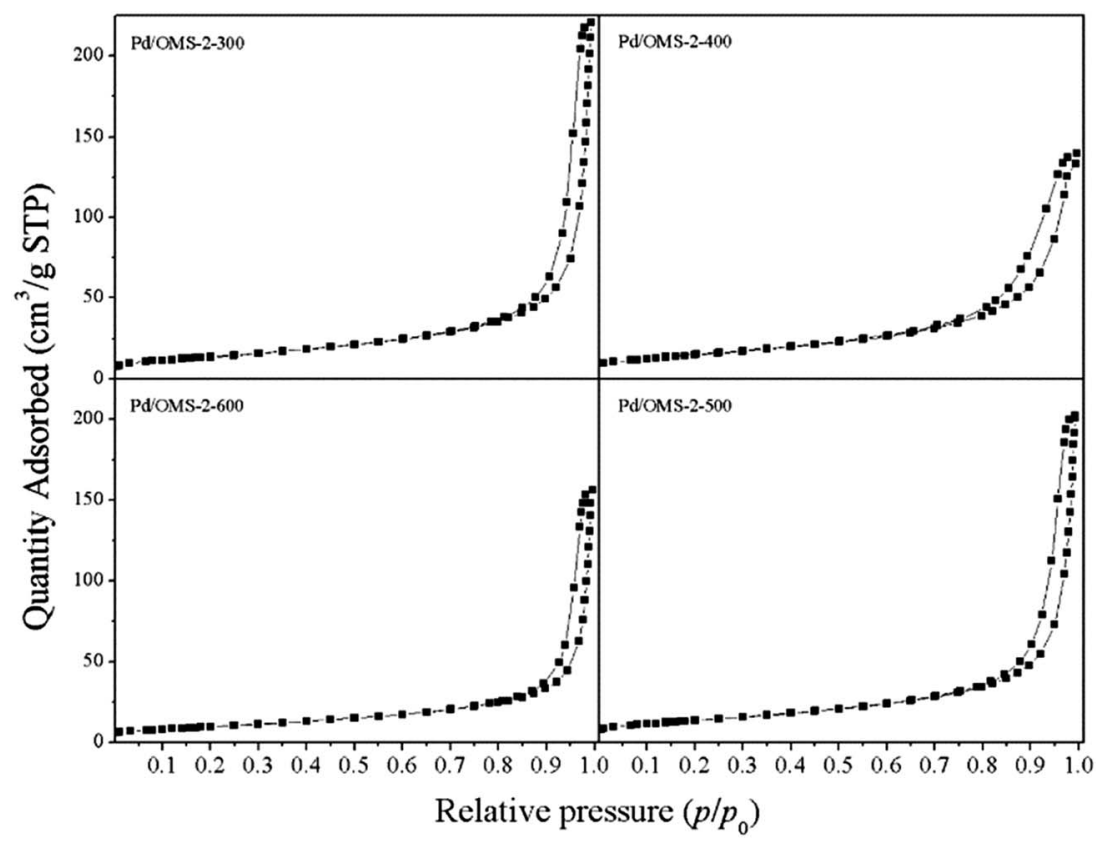

Fig. $3 \quad \mathrm{~N}_{2}$ adsorption-desorption isotherms of various catalysts. 


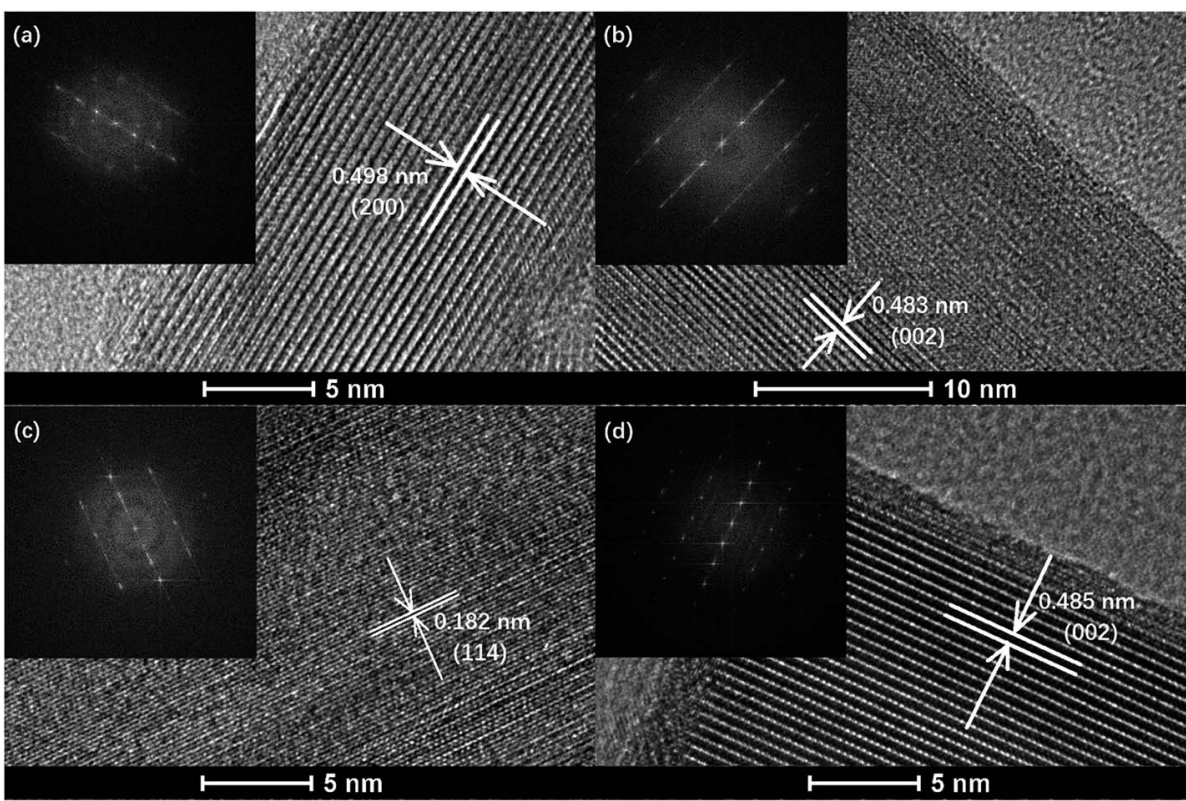

Fig. 4 HR-TEM images of (a) Pd/OMS-2-300, (b) Pd/OMS-2-400, (c) Pd/OMS-2-500, (d) Pd/OMS-2-600.

Table 1 Specific surface area (SSA), pore volume and average pore size of various samples

\begin{tabular}{llll}
\hline Samples & $\begin{array}{l}\mathrm{SSA}^{a} \\
\left(\mathrm{~m}^{2} \mathrm{~g}^{-1}\right)\end{array}$ & $\begin{array}{l}\text { Pore volume }^{b} \\
\left(\mathrm{~m}^{3} \mathrm{~g}^{-1}\right)\end{array}$ & $\begin{array}{l}\text { Average pore size } \\
(\mathrm{nm})\end{array}$ \\
\hline Pd/OMS-2-300 & 49.4 & 0.311 & 25.2 \\
Pd/OMS-2-400 & 53.5 & 0.195 & 14.5 \\
Pd/OMS-2-500 & 47.0 & 0.297 & 24.8 \\
Pd/OMS-2-600 & 35.0 & 0.211 & 24.1
\end{tabular}

${ }^{a}$ Specific surface area (SSA) was calculated from Brunauer-EmmettTeller (BET) equation. ${ }^{b}$ Pore volume was calculated from single point adsorption total pore volume of pores less than $189.4 \mathrm{~nm}$ width at $P /$ $P_{0}=0.990000000 .{ }^{c}$ Average pore size was determined from adsorption average pore diameter ( $4 V / A$ by BET).

further discuss the speculation mentioned above. It can be seen from Table 1 that the specific surface areas (SSA) of different samples follow the order of: Pd/OMS-2-400 > Pd/OMS-2-300 > Pd/OMS-2-500 > Pd/OMS-2-600. The present research indicates that SSA has no significant effect on the catalytic activity of the Pd/OMS-2 catalysts.

\subsection{High resolution transmission electron microscope (HR- TEM) analysis}

High resolution transmission electron microscope (HR-TEM) images of various samples are shown in Fig. 4. All samples show a dispersed regular well-crystalline nanorod structure with a single or multiple crystal plane exposed. The diameter of the samples ranges from 35 to $55 \mathrm{~nm}$ and the length of the samples ranges from 200 to $400 \mathrm{~nm}$ (ESI Fig. S3 to S6†). No obvious aggregated particles of palladium species could be found, indicating high dispersion of the palladium species despite a high calcination temperature above $500^{\circ} \mathrm{C}$. A minority of semi crystals and irregular accumulated nanoparticles could be observed from all the samples. The irregular dispersed nanorods and accumulated nanoparticles may contribute to the interparticle space, as described in $\mathrm{N}_{2}$ adsorption-desorption analysis (Fig. 3 and Table 1). It should be noted that Pd/OMS-2300 and Pd/OMS-2-400 show a relatively regular well-crystalline structure with the regular shape of a long longitude nanorod (ESI Fig. S3 to S6†).

\subsection{X-ray photoelectron spectroscopy (XPS) analysis}

X-ray photoelectron spectroscopy (XPS) analysis was employed to analyze the chemical state and atomic concentration of surface palladium, manganese, and oxygen species. ULVAC-PHI MultiPak $^{\mathrm{TM}}$ Software Manual (Version 9, ULVAC-PHI Inc.) has been utilized to analyze the surface atomic concentration. It has also been reported that surface molar ratios of oxygen vacancies $\left(\mathrm{Mn}^{3+} / \mathrm{Mn}^{4+}\right), \quad \mathrm{Mn}^{\mathrm{n}+} / \mathrm{Mn}_{\text {total }}$ and $\mathrm{O}_{\text {adsorbed }} / \mathrm{O}_{\text {lattice }}$ have an important influence on oxygen storage and transfer capacity over multi-valence manganese oxides due to the dynamic balance of $\mathrm{Mn}^{\mathrm{n}+} \stackrel{\mathrm{e}^{-}}{\longleftrightarrow} \mathrm{Mn}^{(n-1)+}$ and $-\mathrm{Mn}^{4+}-\mathrm{O}^{2-}-\mathrm{Mn}^{4+}-\rightarrow$ $-\mathrm{Mn}^{3+}-\mathrm{O}-\mathrm{Mn}^{3+}-+1 / 2 \mathrm{O}_{2}$ in the presence of gaseous oxygen. ${ }^{\mathbf{1 6}}$ Therefore, the present study has analyzed the surface molar ratios of $\mathrm{Mn}^{2+} / \mathrm{Mn}_{\text {total }}, \mathrm{Mn}^{3+} / \mathrm{Mn}_{\text {total }}, \mathrm{Mn}^{4+} / \mathrm{Mn}_{\text {total }}$ and $\mathrm{O}_{\text {adsorbed }} /$ $\mathrm{O}_{\text {lattice }}$ Over the various catalysts using XPS PeakFit (Version 4.0, AISN Software Inc.) software.

The surface atomic ratios of $\mathrm{Mn}^{2+} / \mathrm{Mn}_{\text {total }}, \mathrm{Mn}^{3+} / \mathrm{Mn}_{\text {total }}$ and $\mathrm{Mn}^{4+} / \mathrm{Mn}_{\text {total }}$ were calculated as follows:

$$
\begin{aligned}
& \mathrm{Mn}^{2+} / \mathrm{Mn}_{\text {total }}=\frac{S_{1}}{S_{1}+S_{2}+S_{3}} \\
& \mathrm{Mn}^{3+} / \mathrm{Mn}_{\text {total }}=\frac{S_{1}}{S_{1}+S_{2}+S_{3}}
\end{aligned}
$$




$$
\mathrm{Mn}^{4+} / \mathrm{Mn}_{\text {total }}=\frac{S_{1}}{S_{1}+S_{2}+S_{3}}
$$

where $S_{1}, S_{2}$ and $S_{3}$ represent the corresponding peak areas of $\mathrm{Mn}^{2+}, \mathrm{Mn}^{3+}$ and $\mathrm{Mn}^{4+}$, respectively.

The surface atomic ratios of $\mathrm{O}_{\text {adsorbed }} / \mathrm{O}_{\text {lattice }}$ were calculated using the following equation:

$$
\mathrm{O}_{\text {adsorbed }} / \mathrm{O}_{\text {total }}=\frac{S_{\text {adsorbed }}}{S_{\text {adsorbed }}+S_{\text {lattice }}}
$$

where $S_{\text {adsorbed }}$ and $S_{\text {lattice }}$ are the peak areas corresponding to $\mathrm{O}^{2-}$ and $\mathrm{OH}^{-} / \mathrm{CO}_{3}{ }^{2-}$, respectively.

It can be seen from Fig. 5 that $\mathrm{Pd} 3 \mathrm{~d}_{5 / 2}$ and $\mathrm{Pd} 3 \mathrm{~d}_{3 / 2}$ peaks located at $337.32 \pm 0.04 \mathrm{eV}$ and $342.65 \pm 0.04 \mathrm{eV}$, respectively, indicate the existence of the $\mathrm{Pd}$ (II) state..$^{17,18}$ No characteristics of $\mathrm{Pd}(\mathrm{Iv})$ species could be observed from the peaks of the Pd $3 \mathrm{~d}$ spectrum. ${ }^{19}$ It should also be noted that the present XPS technique has insufficient evidence to confirm the existence of strong metal-support interacted Pd(II) (Pd SMSI $_{\text {S }}$. XPS spectra of Mn 2p in Fig. 6 showed 2p peaks of Mn located at $640.90 \pm 0.04 \mathrm{eV}, 642.10$ $\pm 0.04 \mathrm{eV}$ and $643.50 \pm 0.04 \mathrm{eV}$ indicating that $\mathrm{Mn}$ species coexisted in the multi-valence states of $\mathrm{Mn}^{2+}, \mathrm{Mn}^{3+}$ and $\mathrm{Mn}^{4+} \cdot .^{20,21}$ The O 1s XPS spectra of the catalysts can be resolved into two peaks, as shown in Fig. 7. The peaks at 529.76 $\pm 0.03 \mathrm{eV}$ (denoted by $\left.\mathrm{O}_{\text {lattice}}\right)$ could be attributed to the characteristic peak of metaloxygen (the lattice oxygen, $\mathrm{O}^{2-}$ ), while the peaks at $531.5 \mathrm{eV}$ (denoted by $\mathrm{O}_{\text {adsorbed }}$ ) are generally regarded as the surface chemisorbed oxygen $\left(\mathrm{OH}^{-}\right.$or $\left.\mathrm{CO}_{3}{ }^{2-}\right){ }^{22,23}$

Surface $\mathrm{Mn}^{2+}: \mathrm{Mn}^{3+}: \mathrm{Mn}^{4+}$ molar ratios of all samples are listed in Table 2. No obviously different molar ratios of $\mathrm{Mn}^{2+}: \mathrm{Mn}^{3+}: \mathrm{Mn}^{4+}$ could be observed from Pd/OMS-2-300, Pd/OMS-2-400 or Pd/OMS-2-500, indicating the maintenance of the OMS-2 structure. ${ }^{20}$ Rare surface potassium $\left(\mathrm{K}^{+}\right)$could be seen from Pd/OMS-2-300 and Pd/OMS-2-400, indicating the occupation of $\mathrm{K}^{+}$in the $2 \times 2$ microchannels of the OMS-2 structure. However, Pd/OMS-2-500, Pd/OMS-2-600 showed a sudden emergence of surface potassium $\left(\mathrm{K}^{+}\right)$. In addition,

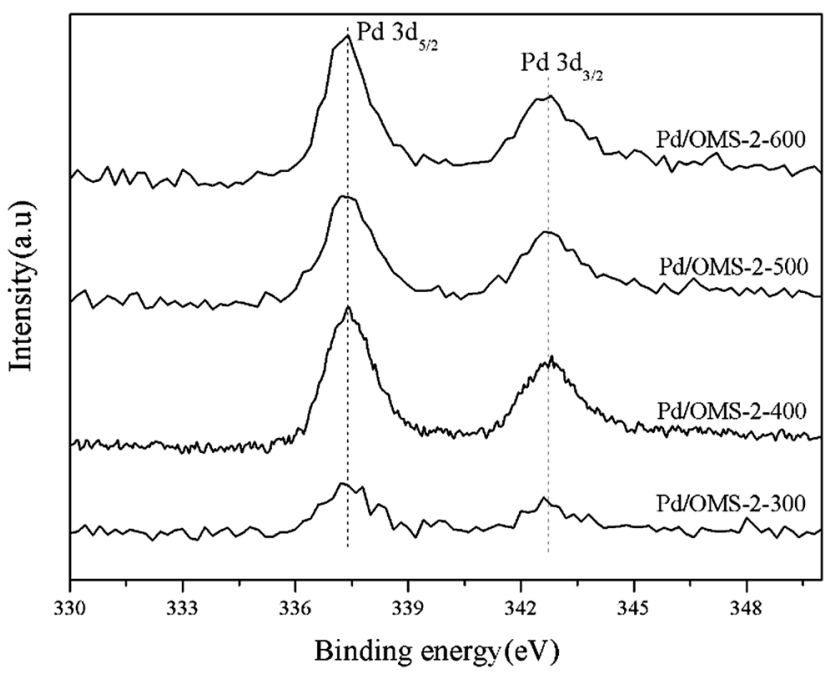

Fig. 5 XPS spectra of Pd 3d over various samples.

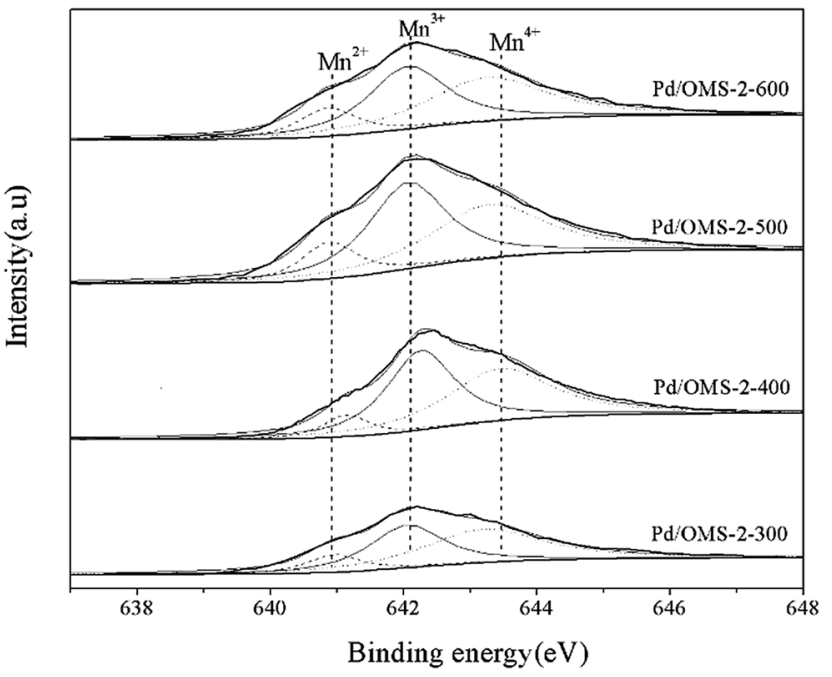

Fig. 6 XPS spectra of Mn 2p over various samples.

surface atomic ratios of palladium increased with the elevation of the thermal-treatment temperature above $400{ }^{\circ} \mathrm{C}$. There was a potential spill-over effect of $\mathrm{K}^{+}$from the $2 \times 2$ microchannels and/or decomposition of strong metal-support interacted palladium $\left(\mathrm{Pd}_{\mathrm{SMSI}}\right)$ during the thermal treatment process at 500 to $600{ }^{\circ} \mathrm{C}$. Above all, it could be concluded that an increase in thermal treatment temperature from 300 to $500{ }^{\circ} \mathrm{C}$ is preferred to improve surface palladium and potassium species, while the catalytic activity of CO oxidation also increased with the elevation of the calcination temperature from 300 to $500{ }^{\circ} \mathrm{C}$.

It could be observed from Table 2 that Pd/OMS-2-400 and Pd/OMS-2-500 show approximately $2: 1$ surface O/Mn atomic ratios, while the surface $\mathrm{O} / \mathrm{Mn}$ atomic ratios $\mathrm{Pd} / \mathrm{OMS}-2-300$ and $\mathrm{Pd} / \mathrm{OMS}-2-600$ are 3.48 and 2.58 , respectively, which are obviously higher than the stoichiometric ratio of $\mathrm{K}_{2-x} \mathrm{Mn}_{8} \mathrm{O}_{16}$. Is known that a majority of surface hydroxyl groups $(-\mathrm{OH})$ may contribute to an increase in surface oxygen of the OMS-2 structure. While it is also known that a higher thermal treatment temperature may

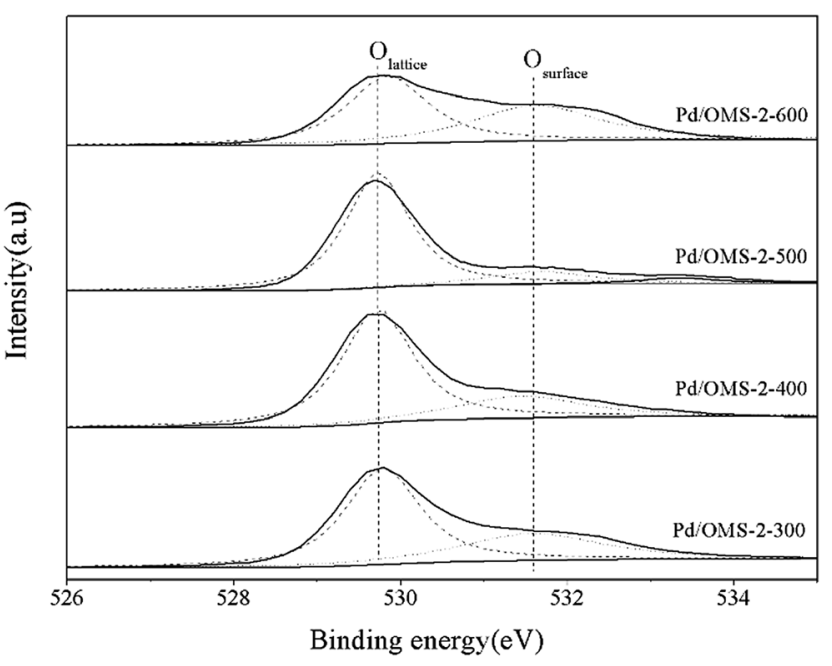

Fig. 7 XPS spectra of $O 1$ s over various samples. 
Table 2 Surface atomic ratios of $\mathrm{Mn}^{2+} / \mathrm{Mn}_{\text {total, }} \mathrm{Mn}^{3+} / \mathrm{Mn}_{\text {total, }} \mathrm{Mn}^{4+} / \mathrm{Mn}_{\text {total, }} \mathrm{O}_{\text {adsorbed }} / \mathrm{O}_{\text {lattice }}$ and surface atomic concentrations (\%) of various samples

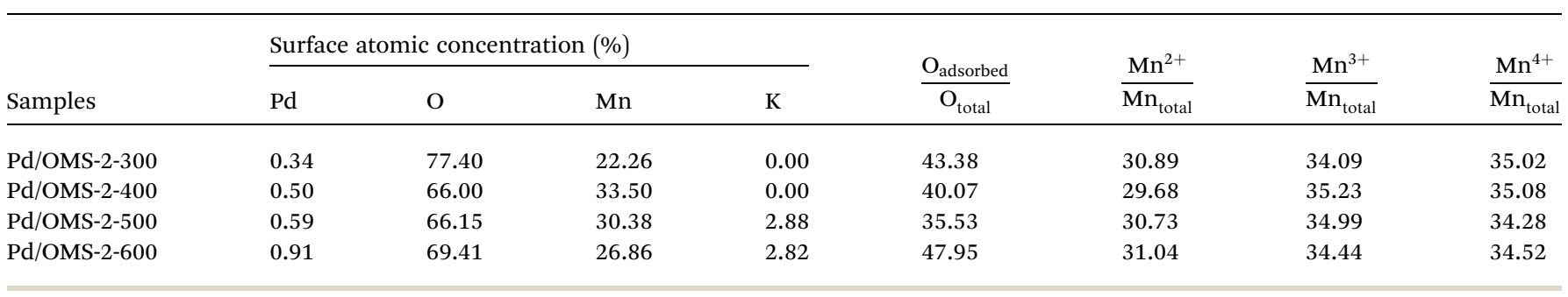

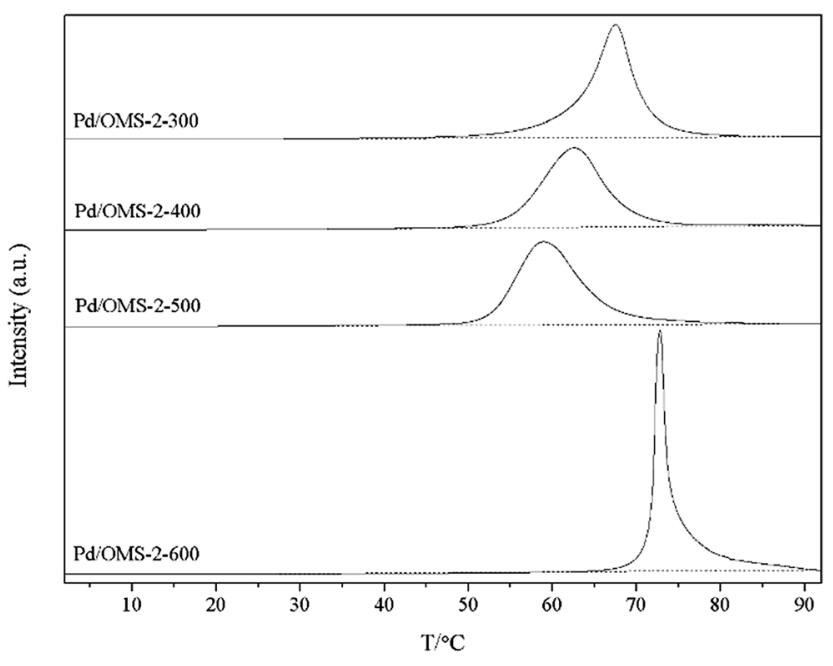

Fig. 8 Low-temperature $\mathrm{H}_{2}$-TPR profiles of the various samples.

lead to a decrease in surface hydroxyl groups $(-\mathrm{OH})$ of metal oxide. $^{22}$ Therefore, it could be speculated that surface $-\mathrm{OH}$ contributed to the nonstoichiometric $\mathrm{O} / \mathrm{Mn}$ atomic ratios of $\mathrm{Pd} /$ OMS-2-300. It should be noted that our XRD analysis (Fig. 2) indicates that $\mathrm{Pd} / \mathrm{OMS}-2-600$ exhibits two major crystalline phases of $\mathrm{Mn}_{2} \mathrm{O}_{3}$ and $\mathrm{K}_{2-x} \mathrm{Mn}_{8} \mathrm{O}_{16}$, which indicate a total stoichiometric $\mathrm{O} / \mathrm{Mn}$ ratio of less than 2.0. However, as a matter of fact, Pd/OMS-2-600 shows a surface $\mathrm{O} / \mathrm{Mn}$ ratio of 2.58. Therefore, further analysis of structural and chemical data (Raman and $\mathrm{H}_{2}-$ TPR. etc.) are expected. Although it is too early to conclude a defined correlation of catalytic activity between $\mathrm{O}_{\text {adsorbed }} / \mathrm{O}_{\text {lattice, }}$, $\mathrm{O} / \mathrm{Mn}$ atomic ratios and catalytic activity of $\mathrm{CO}$ oxidation, to our great interest, Pd/OMS-2-400 and Pd/OMS-2-500 exhibit approximately $2: 1$ surface $\mathrm{O} / \mathrm{Mn}$ atomic ratios of OMS-2 and an obviously higher catalytic activity than Pd/OMS-2-300 or Pd/OMS-2600. Further exploration of the redox properties $\left(\mathrm{H}_{2}-\mathrm{TPR}\right)$ and laser Raman are expected.

\section{6 $\quad \mathrm{H}_{2}$ temperature programmed reduction analysis ( $\mathrm{H}_{2}$-TPR)}

Low-temperature programmed reduction (low-temperature $\mathrm{H}_{2}$-TPR) has been carried out to explore the redox properties of surface palladium species under elevated temperatures in $\mathrm{H}_{2} /$ Ar. It can be seen from Fig. 8 that all samples show obvious peaks of $\mathrm{H}_{2}$ consumption at 65 to $75{ }^{\circ} \mathrm{C}$, indicating the reduction of PdO and the Pd-assisted reduction of surface $\mathrm{MnO}_{x}$-interacted $\mathrm{Pd}(\mathrm{II}) .{ }^{11,23}$ Peaks of reduction temperature (Fig. 8 ) shifted in the order Pd/OMS-2-600 $\left(72.8^{\circ} \mathrm{C}\right)>\mathrm{Pd} / \mathrm{OMS}-2-$ $300\left(67.5{ }^{\circ} \mathrm{C}\right)>\mathrm{Pd} / \mathrm{OMS}-2-400\left(62.6^{\circ} \mathrm{C}\right)>\mathrm{Pd} / \mathrm{OMS}-2-500(58.9$ $\left.{ }^{\circ} \mathrm{C}\right)$. No significant differences in peak areas could be observed from any of the samples, indicating the same amount of $\mathrm{H}_{2}$ consumed by $\mathrm{Pd}(\mathrm{II})$ and $\mathrm{Pd}(\mathrm{II})$ interacted surface $\mathrm{MnO}_{x}$ species (for example, Pd-O-Mn structure) (Table 3). Pd/OMS-2-300 $\left(67.5^{\circ} \mathrm{C}\right), \mathrm{Pd} / \mathrm{OMS}-2-400$ and $\mathrm{Pd} / \mathrm{OMS}-2-500$ show relatively flat peaks with a wide full width at half maximum (FWHMs), while Pd/OMS-2-600 shows a sharp increase in peak height and a sharp decrease in full wave at half maximum (FWHM). Above all, compared with other samples, profiles of Pd/OMS-2-600 imply an abrupt alteration in the Pd-support interaction. It is reported that a relatively high calcination temperature may lead to a decrease in the strong palladium-support interaction or the transformation of $\mathrm{Pd}_{\mathrm{SMSI}}$ into dispersed surface $\mathrm{PdO}$ and $\mathrm{Pd}^{0},{ }^{12}$ which could enhance the low-temperature catalytic activity of CO oxidation. ${ }^{24,25}$ Reduction of the co-existing surface $\mathrm{Pd}_{\text {SMSI }}$ and $\mathrm{PdO}$ could be regarded as a potential reason for the broader FWHMs $^{26}$ over Pd/OMS-2-300, Pd/OMS-2-400 and Pd/OMS-2500. Combined with our XRD (Fig. 2) and HR-TEM analysis (Fig. 4), no obvious sintering of the palladium particles could be observed from the Pd/OMS-2-600, due to the low content of palladium. However, sintering of the OMS-2 structure, phase transformation and changes in surface chemical properties (for example, the spill-over of Pd from the $2 \times 2$ tunnels to the surface) at $600{ }^{\circ} \mathrm{C}$ are also potential reasons for the deactivation of Pd/OMS-2-600. In conclusion, an elevated calcination temperature from 300 to $500{ }^{\circ} \mathrm{C}$ is preferred to enhance the redox activity of palladium species, while a higher calcination temperature above $600{ }^{\circ} \mathrm{C}$ may weaken the palladium-support interaction. While it is hard to determine the key factors for the enhanced activity of Pd/OMS-2-500 and deactivation of Pd/OMS2-600 from $\mathrm{H}_{2}$-TPR and XPS analysis.

Table 3 Peak positions and areas of $\mathrm{H}_{2}$ consumption over various samples

\begin{tabular}{llr}
\hline Samples & Peak position $\left({ }^{\circ} \mathrm{C}\right)$ & Area \\
\hline Pd/OMS-2-300 & 67.5 & 1081 \\
Pd/OMS-2-400 & 62.6 & 1074 \\
Pd/OMS-2-500 & 58.9 & 1075 \\
Pd/OMS-2-600 & 72.8 & 999
\end{tabular}




\subsection{Raman analysis}

Confocal micro-spectroscopy Raman spectra are employed to provide complementary structural information of XRD analysis over various Pd/OMS-2 catalysts. Optical microscope images of various samples are shown in Fig. S7(a), S8(a), S9(a), S10(a) (ESI $\dagger$ ). Raman spectra of selected spots1 (Fig. S7(a), S8(a), S9(a), S10(a) $(\mathrm{ESI} \dagger))$ exhibit well-crystalline structure. Distinct peaks of all samples at 636 to $656 \mathrm{~cm}^{-1}$ assignable to the symmetric vibrations of the $\mathrm{A}_{1 \mathrm{~g}}$ stretching mode of the lattice $\mathrm{Mn}-\mathrm{O}$, indicate the existence of an octahedral $\mathrm{MnO}_{6}$ structure with $2 \times 2$ tunnels. ${ }^{\mathbf{1 4 , 1 5}}$ It is hard to give qualitative and quantitative analysis results of surface PdO from the present Raman analysis as the influence of the $\mathrm{Mn}-\mathrm{O} \mathrm{A}_{1 \mathrm{~g}}$ mode at 636 to $656 \mathrm{~cm}^{-1}$ approaches the distinctive Raman mode of PdO. ${ }^{27,32}$ Bands in the region 455-569 $\mathrm{cm}^{-1}$ could be attributed to the asymmetric stretching of bridge oxygen species (Mn-O-Mn), indicating the existence of surface amorphous or semi-crystalline $\mathrm{Mn}_{x} \mathrm{O}_{y}$ species (where $1<x<2,1<y<3$ and $1<y / x<1.5) .{ }^{28}$ It can be seen from Fig. 9(a) that the peak of $\mathrm{Pd} / \mathrm{OMS}-2-600$ at $348 \mathrm{~cm}^{-1}$ is the out-of-plane bending mode of $\mathrm{Mn}_{2} \mathrm{O}_{3}$, indicating the presence of $\mathrm{Mn}_{2} \mathrm{O}_{3} \cdot{ }^{29}$ Bands of Pd/OMS-2300 and $\mathrm{Pd} / \mathrm{OMS}-2-400$ at $182 \mathrm{~cm}^{-1}$ indicate the presence of an $\mathrm{Mn}-\mathrm{O}-\mathrm{M}$ metal-oxygen chain interacting with the occupation of $\mathrm{K}^{+}$in the $2 \times 2$ tunnels. $^{30,31}$

Shoulders at $578 \mathrm{~cm}^{-1}$ corresponding to the symmetric vibrations of the $\mathrm{F}_{2 \mathrm{~g}}$ mode of the lattice $\mathrm{Mn}-\mathrm{O}$ could be observed from Pd/OMS-2-300 and Pd/OMS-2-400 (Fig. 9(a)), ${ }^{14}$ indicating the existence of the well-developed tetragonal structure of $\mathrm{MnO}_{6}$ octahedral chains with $\mathrm{K}^{+}$occupied inside the $2 \times 2$ tunnels. ${ }^{32,33}$ This slight $\mathrm{F}_{2 \mathrm{~g}}$ mode of the lattice $\mathrm{Mn}-\mathrm{O}$ peak could not be observed from the spectra of Pd/OMS-2-500 or Pd/OMS-2-600. Moreover, bands of $\mathrm{Pd} / \mathrm{OMS}-2-300$ and Pd/OMS-2-400 at $182 \mathrm{~cm}^{-1}$ and $578 \mathrm{~cm}^{-1}$ corresponding to the $\mathrm{K}^{+}$interacted
Mn-O species could not be observed from Pd/OMS-2-300 or Pd/ OMS-2-400 after heating. Combined with our XPS analysis (Table 2), it is also inferred that Pd/OMS-2-500 and Pd/OMS-2-600 exhibit an abrupt increase in surface potassium and palladium, i.e. a spill-over of palladium and $\mathrm{K}^{+}$from the octahedral $\mathrm{MnO}_{6}$ interacted $2 \times 2$ tunnels, when Pd/OMS- 2 was calcined above $400{ }^{\circ} \mathrm{C}$. It should be noted that Pd/OMS-2-500 exhibits no obvious shifts and the peaks disappear before and after being heated at $450{ }^{\circ} \mathrm{C}$ in Ar. In other words, compared with Pd/OMS-2-300 and Pd/OMS-2-400, Pd/OMS-2-500 exhibits a higher thermal stability.

\section{Discussion}

The gradual evolution of surface species and metal-support interactions with the different thermal-treatment temperatures have been characterized by XPS $\mathrm{H}_{2}$-TPR and Raman analysis. Reduction peaks of $\mathrm{H}_{2}$-TPR over the samples shifted to a lower temperature as the thermal-treatment temperature increased from 300 to $500{ }^{\circ} \mathrm{C}$. An elevated calcination temperature up to $500{ }^{\circ} \mathrm{C}$ is the potential influencing factor for decreasing palladium (or potassium)-support interaction. Raman analysis indicated the decrease (or disappearance) of bands at $182 \mathrm{~cm}^{-1}$ and $578 \mathrm{~cm}^{-1}$ corresponding to the occupation of $\mathrm{K}^{+}$in the $2 \times$ 2 tunnels. XPS indicated no obvious proofs of $\mathrm{Pd}_{\mathrm{SMSI}}$ and the differences in surface palladium (and potassium) atomic ratios over all the samples. However, all the samples exhibit the same peak areas of $\mathrm{H}_{2}$-TPR, indicating that all samples have the same content of $\mathrm{H}_{2}$-activated $\operatorname{Pd}(\mathrm{II})$ (Table 3 ). Above all, it could be speculated that the spill-over of potassium and palladium from the tunnels to the outer surface happened with the elevation in calcination temperature from 300 to $500{ }^{\circ} \mathrm{C}$. Despite the same content of total palladium and $\mathrm{H}_{2}$-activated $\mathrm{Pd}(\mathrm{II})$, the increase

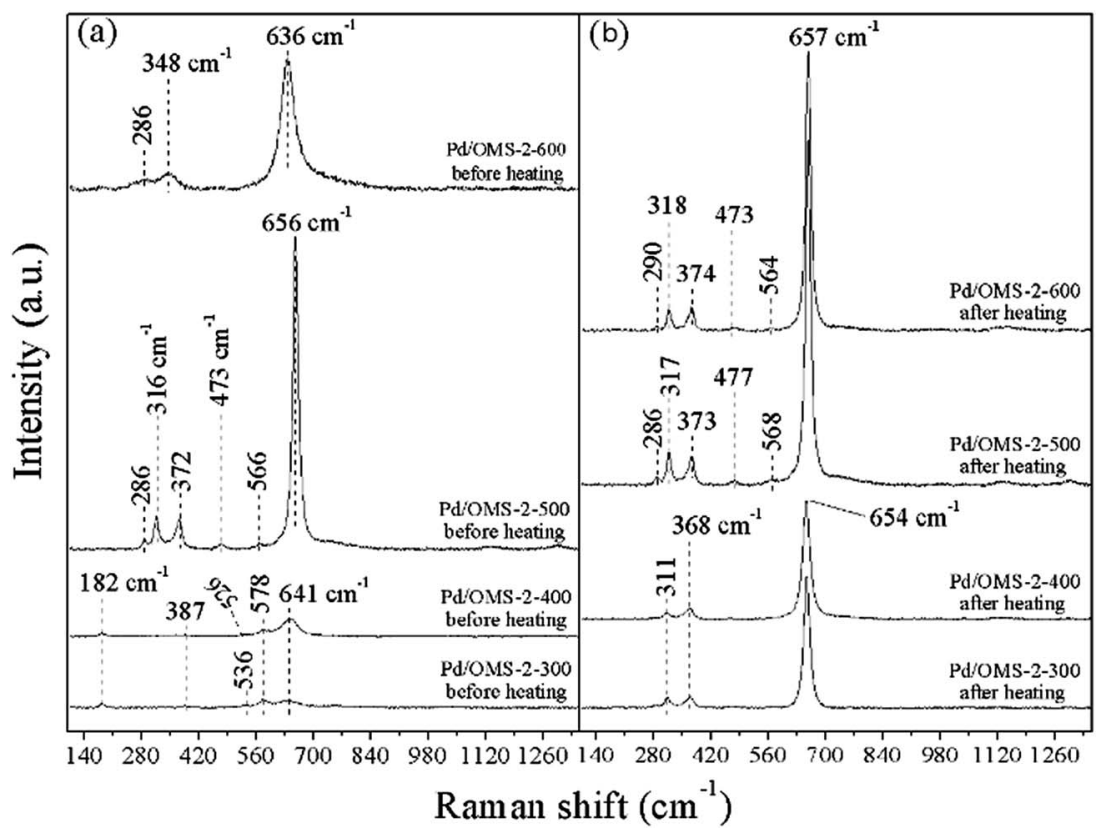

Fig. 9 Raman spectroscopy of various samples (a) before heating (room temperature), (b) cooled to room temperature after being heated at $450{ }^{\circ} \mathrm{C}$ (testing conditions: in Ar atmosphere). 
in surface Pd species (proved by XPS analysis) is generally regarded as a key factor in improving $\mathrm{CO}$ catalytic oxidation. ${ }^{12,24,25}$ Combined with the XPS, XRD and $\mathrm{H}_{2}$-TPR analysis, an abrupt increase in surface oxygen and palladium, the phase transformation of $\mathrm{K}_{2-x} \mathrm{Mn}_{8} \mathrm{O}_{16} \rightarrow \mathrm{Mn}_{2} \mathrm{O}_{3}$, as well as an alteration in palladium-support interactions happened when the calcination temperature shifted from 500 to $600{ }^{\circ} \mathrm{C}$. Despite the increase in surface palladium at a thermal-treatment temperature of $600{ }^{\circ} \mathrm{C}$, the sintering effect plays a key role in the deactivation over Pd/OMS-2-600. But it is beyond the scope of the present research to probe the detailed sintering effects on the deactivation of Pd/OMS-2-600 catalysts. Previous research on the catalytic oxidation of $\mathrm{CO}$ over manganese oxides and manganese oxides supported noble-metal catalysts has been listed in Table S1 in ESI. $\dagger$

\section{Conclusions}

The present research has explored a facile thermal treating process on the catalytic activity of CO oxidation over OMS-2 supported palladium catalysts. A relatively high calcination temperature up to $500{ }^{\circ} \mathrm{C}$ is preferred to improve surface palladium atomic ratios and catalytic activity of the Pd/OMS-2 catalyst. In addition, an elevated calcination temperature up to $500{ }^{\circ} \mathrm{C}$ led to a decrease in surface $\mathrm{O}_{\text {adsorbed }}$ and palladium (or potassium)-support interaction. Spill-over of potassium and palladium happened when the calcination temperature shifted from 400 to $500{ }^{\circ} \mathrm{C}$. A higher calcination temperature above $500{ }^{\circ} \mathrm{C}$ may lead to the abrupt alteration of palladium-support interactions and a decrease in the catalytic activity. Phase transformation of $\mathrm{K}_{2-x} \mathrm{Mn}_{8} \mathrm{O}_{16} \rightarrow \mathrm{Mn}_{2} \mathrm{O}_{3}$ happened as well. The present research indicates that an optimal thermal-treatment temperature $\left(500{ }^{\circ} \mathrm{C}\right)$ existed which was attributed to the optimal surface physiochemical properties of Pd/OMS-2-500 and complete $\mathrm{CO}$ conversion at $35{ }^{\circ} \mathrm{C}$.

\section{Conflicts of interest}

There are no conflicts to declare.

\section{Acknowledgements}

This work is supported by the National Natural Science Foundation of China (No. 21666014); The Analysis and Testing Foundation of Kunming University of Science and Technology (No. 2016P201501107004).

\section{References}

1 R. Prasad and P. Singh, Catal. Rev., 2012, 54(2), 224-279.

2 B. Min and C. FrLiuiend, Chem. Rev., 2007, 107(6), 27092724.

3 T. Takei, T. Akita, I. Nakamura, T. Fujitani, M. Okumura, K. Okazaki, J. Huang, T. Ishida and M. Haruta, Adv. Catal., 2012, 55, 1-126.

4 X. Zhang, Z. Qu, F. Yu and Y. Wang, Chin. J. Catal., 2013, 34(7), 1277-1290.
5 T. Nguyen, F. Morfin, M. Aouine, F. Bosselet, J. Rousset and L. Piccolo, Catal. Today, 2015, 253, 106-114.

6 C. Wang, A. J. Binder, T. J. Toops, J. Lauterbach and E. Sasmaz, Emiss. Control Sci. Technol., 2017, 3, 37-46.

7 S. Kato, R. Fujimaki, M. Ogasawara, T. Wakabayashi, Y. Nakahara and S. Nakata, Appl. Catal., B, 2009, 89, 183-188.

8 S. Wang, N. Li, L. Luo, W. Huang, Z. Pu, Y. Wang, G. Hu, M. Luo and J. Lu, Appl. Catal., B, 2014, 144, 325-332.

9 C. Zhang, C. Wang, W. Zhan, Y. Guo, Y. Guo, G. Lu, A. Baylet and A. Giroir-Fendler, Appl. Catal., B, 2013, 129, 509-516.

10 X. Chen, Y. Shen, S. Suib and C. Young, Chem. Mater., 2002, 14, 940-948.

11 Q. Zhang, Q. Liu, P. Ning, X. Liu, L. Xu, Z. Song, Y. Duan and T. Zhang, Res. Chem. Intermed., 2017, 43(4), 2017-2032.

12 S. Hinokuma, H. Fujii, M. Okamoto, K. Ikeue and M. Machida, Chem. Mater., 2010, 22, 6183-6190.

13 S. Hinokuma, H. Fujii, Y. Katsuhara, K. Ikeue and M. Machida, Catal. Sci. Technol., 2014, 4, 2990-2996.

14 C. Calvert, R. Joesten, K. Ngala, J. Villegas, A. Morey, X. Shen and S. L. Suib, Chem. Mater., 2008, 20, 6382-6388.

15 S. Dharmarathna, C. K. King'ondu, W. Pedrick, L. Pahalagedara and S. L. Suib, Chem. Mater., 2012, 24(4), 705-712.

16 J. Hou, Y. Li, L. Liu, L. Ren and X. Zhao, J. Mate. Chem. A, 2013, 1(23), 6736-6741.

17 K. Priolkar, P. Bera, P. Sarode, M. Hegde, S. Emura, R. Kumashiro and N. P. Lalla, Chem. Mater., 2002, 14, 2120-2128.

18 S. Sharma, B. Devu Mukri and M. S. Hegde, Dalton Trans., 2011, 40, 11480-11489.

19 Y. Zhou, X. Liu, Q. Zhang, Q. Liu, Z. Song and P. Ning, Res. Chem. Intermed., 2017, 43(22), 1-19.

20 X. Meng, J. Zhang, B. Chen, Z. Jing and P. Zhao, Catal. Sci. Technol., 2016, 6, 890-896.

21 E. S. Ilton, J. E. Post, P. J. Heaney, F. T. Ling and S. N. Kerisit, Appl. Surf. Sci., 2016, 366, 475-485.

22 Q. Zhang, X. Liu, P. Ning, Z. Song, H. Li and J. Gu, Catal. Sci. Technol., 2015, 5, 2260-2269.

23 X. Liu, P. Ning, L. Xu, Q. Liu, Z. Song and Q. Zhang, RSC Adv., 2016, 6, 41181-41188.

24 A. I. Boronin, E. M. Slavinskaya, I. G. Danilova, R. V. Gulyaev, Y. I. Amosov, P. A. Kuznetsov, I. A. Polukhina, S. V. Koscheev, V. I. Zaikovskii and A. S. Noskov, Catal. Today, 2009, 144, 201-211.

25 E. M. Slavinskaya, R. V. Gulyaev, A. V. Zadesenets, O. A. Stonkus, V. I. Zaikovskii, Y. V. Shubin, S. V. Korenev and A. I. Boronin, Appl. Catal., B, 2015, 91, 166-167.

26 L. Meng, A. P. Jia, J. Q. Lu, L. F. Luo, W. X. Huang and M. F. Luo, J. Phys. Chem. C, 2011, 115(40), 19789-19796.

27 A. Baylet, P. Marécot, D. Duprez, P. Castellazzi, G. Groppi and P. Forzatti, Phys. Chem. Chem. Phys., 2011, 13, 46074613.

28 J. Xu, Y. Deng, X. Zhang, Y. Luo, W. Mao, X. Yang, L. Ouyang, P. Tian and Y. Han, ACS Catal., 2014, 4, 4106-4115.

29 J. Xu, Y. Deng, Y. Luo, W. Mao, X. Yang and Y. Han, J. Catal., 2013, 300, 225-234. 
30 C. Wang, J. Ma, F. Liu, H. He and R. Zhang, J. Phys. Chem. C, 2015, 119, 23119-23126.

31 S. Cheng, L. Yang, D. Chen, X. Ji, Z. Jiang, D. Ding and M. Liu, Nano Energy, 2014, 9, 161-167.
32 L. Liu, Y. Song, Z. Fu, Q. Ye, S. Cheng, T. Kang and H. Dai, Appl. Surf. Sci., 2017, 396, 599-608.

33 R. Wang and J. Li, Environ. Sci. Technol., 2010, 44, 42824287. 